\title{
Experiences and lessons in stakeholder engagement in environmental evidence synthesis: a truly special series
}

\author{
Neal R. Haddaway ${ }^{1 *}$ and Sally Crowe ${ }^{2}$
}

The importance of stakeholder engagement has been stressed from the beginning of the evidence synthesis movement in conservation biology [1]. Since then, as the number of experienced systematic reviewers grows yearon-year, so too does the collective experience of practical engagement activities. This special series represents where we are today: a collection of reflections and best practices honed as a result of challenging and rewarding experience. The conclusion from these papers is clear: do it, do it properly, report it. The series is a vital tome for all reviewers and, we hope, a catalyst for improving conduct and reporting of stakeholder engagement in evidence synthesis.

Engaging with stakeholders provides a suite of benefits to research and to stakeholders themselves. It can, for example: increase the quality of research and decision-making; broaden understandings of context and drivers of change; increase legitimacy and acceptance of research; increase research impact; empower stakeholders and facilitate the sharing of information. There is also, arguably, a moral obligation to publish findings freely and engage with the wider community in publicly funded research projects. Without adequate perspectives from stakeholders we run the risk of pursuing research goals that don't address issues that are important to the public and other end users. Furthermore, engagement with stakeholders offers the opportunity to raise public awareness of both environmental issues and the research we conduct as scientists. This may also help create a culture of ownership of some of the solutions that may propel research outcomes into environmental change and impact. However, "one does not simply walk into

\footnotetext{
*Correspondence: neal_haddaway@hotmail.com

${ }^{1}$ Mistra EviEM, Stockholm Environment Institute, Box 24218,

10451 Stockholm, Sweden

Full list of author information is available at the end of the article
}

Mordor" [2]: balanced, unbiased and effective stakeholder engagement requires considerable resources and careful planning.

Many of the early systematic reviews in the field of conservation and environmental management were academic endeavours aimed at testing the framework of systematic reviews within a novel discipline. As such, stakeholder engagement was perhaps not a priority. Since these early days, reviews have devoted little space to explanations of stakeholder engagement activities: such efforts were implicit or referred to the origin of the question, setting of the scope and sources of funding. Until very recently, there was no requirement in systematic reviews published by the Collaboration for Environmental Evidence (CEE) to mention stakeholder engagement efforts, although this Special Series is helping to drive change.

Although engagement would differ substantially between reviews intended to be academic goods, private goods and public goods, each review has its own set of stakeholders. Transparency about how these stakeholders interact with the review would expand the principles of systematic review methodology across the synthesis process, from question inception to communication. Transparency and shared learning are at the heart of recently published international guidelines for improving the reporting of stakeholder involvement in health and social care research [3]. The editors take the view that these (especially the 'GRIPP 2 short form') could assist systematic reviewers in focusing their reporting of stakeholder engagement in ways that are specific to their experience as reviewers and help the research community at large.

This special series collates commentaries from a diverse range of authors with experience of evidence synthesis and various aspects of stakeholder engagement. It also represents the culmination of several years of work by the CEE Stakeholder Engagement Methods 
Group, formally established in 2015 following a series of workshops in South Africa in late 2014. This group aims to investigate and promote best practices in involving stakeholders in systematic reviews and maps. The papers presented within this series are, in part, produced by the Methods Group and its members, but are supplemented by many contributions from other experts. Commentaries range from descriptions of groups' experiences engaging with stakeholders in evidence syntheses to guidance on methods for balanced and unbiased multidirectional interaction with stakeholders across the review process. Individually, these manuscripts provide sage advice for specific aspects of stakeholder engagement. Collectively, this series represents a huge step forwards in the field of evidence synthesis: a go-to guide and reference for those wishing to undertake effective, reliable and efficient stakeholder engagement within a systematic review or map.

Several key themes emerge across the papers in this series. First, considering the importance of stakeholder engagement should be an integral part of all reviews, but the degree and type of stakeholder engagement realised will depend on the exact nature of the review. Second, there is sometimes a need to adapt review methodology for the needs of specific stakeholders; identifying when reviews should be 'gold standard' reviews (public goods), and when reviews should be adapted for specific stakeholder needs (private goods), for example emphasising co-production. Third, that we may benefit from expanding our definition of who/what we count as stakeholders in our reviews; something particularly important for public goods reviews. Fourth, that engaging with stakeholders in an open way that avoids tokenism (the tickbox approach) is not only vital throughout the review process, from planning to communication, but also requires careful planning and integration into review processes and workflows.

We hope that the legacy of this series will grow and develop, providing useful guidance and insights into best practices (and indeed experiences of practices that haven't worked well for whatever reason). We hope this will continue to be overseen by the CEE Stakeholder Engagement Methods Group (visit http://www. environmentalevidence.org/method-groups for more information) and we encourage those with interest and experience to join us. We aim to raise the transparency, balance, openness and minimisation of bias in stakeholder engagement activities across evidence synthesis in the field of conservation and environmental management, amongst others. We hope you enjoy reading these articles as much as we have!

\section{Authors' contributions}

$\mathrm{NRH}$ developed the concept for this manuscript and the special series. NRH and SC drafted the manuscript. Both authors read and approved the final manuscript.

\section{Author details}

${ }^{1}$ Mistra EviEM, Stockholm Environment Institute, Box 24218, 10451 Stockholm, Sweden. ${ }^{2}$ Crowe Associates, 15 Chinnor Rd, Thame OX9 3LW, UK.

\section{Acknowledgements}

We thank the many authors of the wonderful manuscripts in the special series on stakeholder engagement in evidence synthesis in this journal. Their work has been most insightful and a delight to read. We also thank Andrew Pullin and the CEE board for support in producing the special series.

\section{Competing interests}

The authors declare that they have no competing interests.

\section{Availability of data and materials}

Not applicable.

Consent for publication

Not applicable.

Ethics approval and consent to participate Not applicable.

\section{Funding}

The authors received no funding for this manuscript.

\section{Publisher's Note}

Springer Nature remains neutral with regard to jurisdictional claims in published maps and institutional affiliations.

Received: 10 January 2018 Accepted: 16 February 2018

Published online: 21 May 2018

\section{References}

1. Pullin AS, Stewart GB. Guidelines for systematic review in conservation and environmental management. Conserv Biol. 2006;20(6):1647-56.

2. Jackson P. Lord of the rings: the fellowship of the ring. Los Angeles: New Line Cinema, Film; 2001.

3. Staniszewska S, Brett J, Simera I, et al. GRIPP2 reporting checklists: tools to improve reporting of patient and public involvement in research. Res Involv Engagem 2017; 3:13. https://doi.org/10.1186/s40900-017-0062-2. GRIPP 2 http://www.equator-network.org/reporting-guidelines/gripp2reporting-checklists-tools-to-improve-reporting-of-patient-and-publicinvolvement-in-research/.

Submit your next manuscript to BioMed Central and we will help you at every step:

- We accept pre-submission inquiries

- Our selector tool helps you to find the most relevant journal

- We provide round the clock customer support

- Convenient online submission

- Thorough peer review

- Inclusion in PubMed and all major indexing services

- Maximum visibility for your research

Submit your manuscript at www.biomedcentral.com/submit 